\title{
39. PALEOMAGNETIC AND MINERAL MAGNETIC RECORD OF SEDIMENTS FROM THE QUEENS- LAND TROUGH: RESULTS FOR LEG 133, HOLE 823A ${ }^{1}$
}

\author{
C.E. Barton ${ }^{2}$
}

\begin{abstract}
Hole 823A covers the upper $120 \mathrm{~m}$ (Subunits IA and IB) of Site 823 at the bottom of the Queensland Trough. This hole contains an abundance of gravity-flow deposits, but is thought to have a monotonic age sequence. Above $32 \mathrm{mbsf}$, a strong, stable (normal) magnetic remanence having a relatively small viscous remanent magnetization (VRM) is seen. Below $32 \mathrm{mbsf}$, the sediments are subject to widespread VRM, which appears to obliterate the primary magnetization and precludes identification of the Brunhes/ Matuyama boundary. Progressive alternating field (AF) demagnetization is limited to low fields (typically $<400 \mathrm{Oe}$ ) by the weak magnetization in these sediments. As a consequence, the possibility of a high-coercivity component of primary magnetization cannot be ruled out. Lowrie-Fuller tests indicate that this VRM overprinting does not have a multidomain origin. An approximately linear relationship exists between median destructive field (MDF) and the logarithm of the natural remanent magnetization (NRM). Carbonate dilution does not appear to be a dominant factor in controlling variations in concentration-dependent magnetic parameters, such as magnetic susceptibility.

The sedimentological distinction between Subunits IA and IB does not show up in the magnetic record. However, a sharp change in magnetic properties does occur at $32 \mathrm{mbsf}$, with low background magnetizations below this level and high background magnetizations above it. The boundary coincides with a change from thick ( $>10 \mathrm{~cm}$ thick) to thin $(<10 \mathrm{~cm}$ thick) turbidite deposition, and is also near the boundary separating the sulfate-reduction zone in the upper part of the sequence from the sulfate-free zone beneath. The abrupt nature of the magnetic boundary is evidence that nannofossil subzone CN14b is not condensed, but is missing in a hiatus at 32 mbsf.

Nine peaks have been identified in the susceptibility $(K)$ record that are superimposed on "background" signals. ARM/ $K$ ratios are uniformly low for the background sediments below $32 \mathrm{mbsf}$, intermediate for strong susceptibility peaks, and high for background sediments above $32 \mathrm{mbsf}$ and weak susceptibility peaks. Comparisons with results from Site 820 suggest that (1) the background sediments above $32 \mathrm{mbsf}$ and the weak susceptibility peaks carry a stable single-domain magnetization, and (2) the high susceptibility peaks are caused by the addition of a superparamagnetic contribution. Expectations are that the distinctive features of the Hole $823 \mathrm{~A}$ magnetic record are linked to major environmental changes.
\end{abstract}

\section{INTRODUCTION}

Leg 133 Site 823 is located in the central-western Queensland Trough near the deepest part of the basin (Fig. 1). The site is part of a transect of seven sites from the edge of the Great Barrier Reef near Cairns (Site 821), across the Queensland Trough and onto the Queensland Plateau (Site 825). Site 823 was chosen to study the basin-fill sediments and their relationship with other drill sites on the transect, and also to obtain a record of paleoceanographic changes (Davies, McKenzie, Palmer-Julson et al., 1991).

Three holes were drilled at the site: $823 \mathrm{~A}$ from 0 to $119.8 \mathrm{mbsf}$ (103.3\% recovery, 13 cores), $823 \mathrm{~B}$ from 0 to $805.4 \mathrm{mbsf}$ ( $93.7 \%$ recovery, 84 cores), and $823 \mathrm{C}$ from 784.0 to 1011.0 mbsf ( $82 \%$ recovery, 24 cores). Hole $823 \mathrm{~A}$ was drilled in $1638 \mathrm{~m}$ of water at $16^{\circ} 36.981^{\prime} \mathrm{S}, 146^{\circ} 47.037^{\prime} \mathrm{E}$ using a hydraulic piston corer (APC).

The sediments at Site 823 are characterized by an abundance of turbidites, slump deposits, and debris flows - a total of 1860 gravityflow deposits were identified during shipboard studies. Despite this, chronological integrity of the microfossil biostratigraphy exists throughout the sequence, indicating that near-contemporaneous deposition of the redeposited material took place (Davies, McKenzie, Palmer-Julson et al., 1991). Calcareous nannofossil zone CN14b is either missing or highly condensed in core $4 \mathrm{H}$; it is probable that a hiatus occurs at about $32 \mathrm{mbsf}$. The biostratigraphically determined age at the bottom of Hole $823 \mathrm{~A}$ is $1.27 \mathrm{Ma}$ (Shipboard Scientific Party, 1991).

\footnotetext{
${ }^{1}$ McKenzie J.A., Davies, P.J., Palmer-Julson, A., et al., 1993. Proc. ODP, Sci. Results, 133: College Station, TX (Ocean Drilling Project).

${ }^{2}$ Australian Geological Survey Organisation, P.O. Box 378, Canberra, ACT 2601, Australia.
}

Preliminary results obtained from shore-based measurements in subsamples from Hole 823A are summarized in this paper. A complete set of preliminary rock-magnetic measurements has not yet been undertaken, and no systematic magnetic mineralogical analysis has yet been attempted. Interpretations are therefore based on a rather simplistic view of grain-size and coercivity variations in the common iron oxides, and rely heavily on comparison with the properties of similar sediments from Site 820 (Barton et al., this volume). In particular, due consideration has not been given to the role played by iron sulphides, which are almost certainly present. However, the work completed so far is sufficient to describe the main magnetic characteristics of the sequence and to identify particular features that are likely to be a response to major environmental changes.

Conversions from the cgs units (used here) to SI units are as follows: magnetic field strength $(H): 1$ oersted (Oe) corresponds to a flux density of 0.1 millitesla (mT) in a vacuum; intensity of magnetization: 1 microgauss $(\mu \mathrm{G})=10^{-3} \mathrm{~A} / \mathrm{m}$; volume susceptibility $(K)$ : $1 \mathrm{G} / \mathrm{Oe}=1 / 4 \pi$ SI units (dimensionless).

\section{SHIPBOARD MEASUREMENTS}

NRM, magnetic remanence after AF cleaning at 150 Oe peak field, and initial low-field magnetic susceptibility per unit volume $(K)$ had already been measured on board ship at $10-\mathrm{cm}$ intervals in the archive halves of whole cores. The results were reported briefly by the Shipboard Scientific Party (1991). A normal polarity record was obtained throughout the entire length of the sequence recovered, leading the shipboard scientific party to conclude that the sediments either were overprinted by a component of magnetization that could not be removed by $\mathrm{AF}$ cleaning at $150 \mathrm{Oe}$ or were completely remagnetized. 


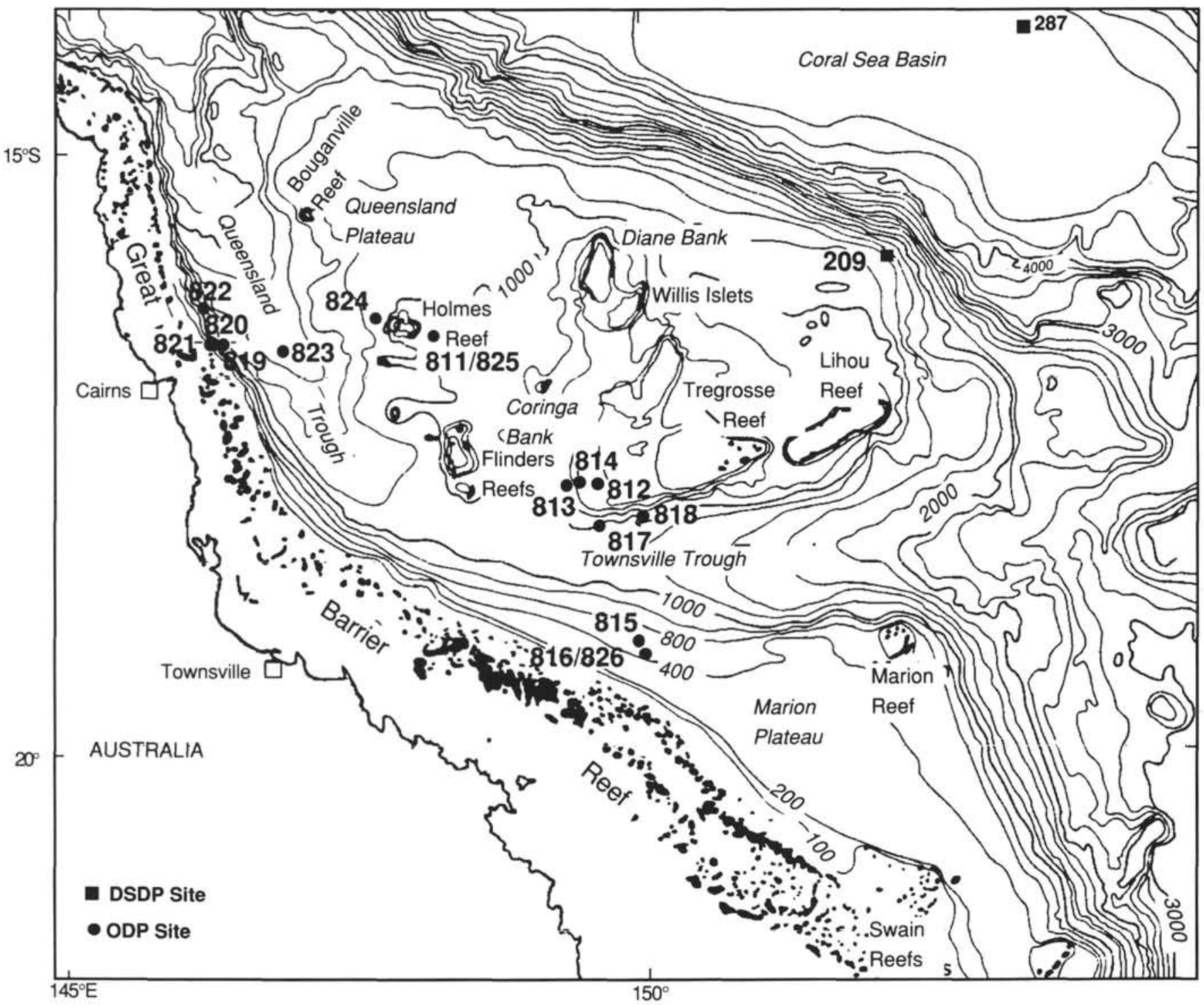

Figure 1. Location and bathymetry (in meters) for Site 823. The site is located in the central-western Queensland Trough near the deepest part of the basin and is part of a transect of seven sites between the Great Barrier Reef and the Queensland Plateau.

\section{SUBSAMPLE MEASUREMENTS}

Subsampling was done on board the ship at 25 -cm intervals $(392$ samples). Two large gaps in the subsampling were seen where slump and debris-flow deposits occurred: from 16 to $25 \mathrm{mbsf}$ (most of Core $3 \mathrm{H}$ ) and from 48 to $53.5 \mathrm{mbsf}$ (the lower half of Core $6 \mathrm{H}$ ). Another two very thick intervals of slump deposits, at about 42 to $72 \mathrm{mbsf}$ and 84.5 to $91 \mathrm{mbsf}$, are indicated in the initial Site 823 report (Shipboard Scientific Party, 1991: Fig. 10, p.692). Subsamples were collected in these two intervals. Sample depths used here refer to subbottom depths to the center of each paleomagnetic specimen, taken as $1 \mathrm{~cm}$ above the bottom of the ODP-listed paleomagnetic sampling interval.

\section{VRM Tests}

The absence of any reversal boundaries in the shipboard data suggests that VRM plays a major role. Tests for VRM were performed using 15 specimens: first they were AF demagnetized in a peak field of $900 \mathrm{Oe}$, then exposed to the laboratory field ( $0.4 \mathrm{Oe})$ in a fixed orientation for up to $2730 \mathrm{hr}$ (about 4 months). The VRM increased nearly linearly with the logarithm of time for all specimens. VRM values reached after 2730 hours, expressed as a percentage of NRM, are summarized in Table 1. These ratios serve as a measure of the VRM coefficient. There does not appear to be an obvious pattern to the distribution of VRM coefficients, and, as evident from Table 1 , the VRM/NRM ratios after $2730 \mathrm{hr}$ do not correlate with either NRM or volume susceptibility.

All VRM/NRM ratios are high, with the VRM after $2730 \mathrm{hr}$ exceeding the NRM value for specimens at $47.28,95.26$, and 113.76 mbsf. If the log-time relationship holds for many thousands of years, then VRM would account for nearly all of the natural remanence of these sediments. This would explain why the Brunhes/Matuyama (B/M) boundary was not recorded.

\section{Natural Remanence}

The NRM intensity record for both whole core (shipboard) and subsample measurements is shown in Figure 2. A sharp magnetic boundary can be seen at 32 mbsf. Above this depth, NRM values are relatively high (typically 10 to $20 \mu \mathrm{G}$ ), with a low between about 16 and $25 \mathrm{mbsf}$, where the slumps and debris flows occur. Below 32 mbsf, NRM intensities are generally low $(0.1$ to $1.0 \mu \mathrm{G})$, with clusters 
A

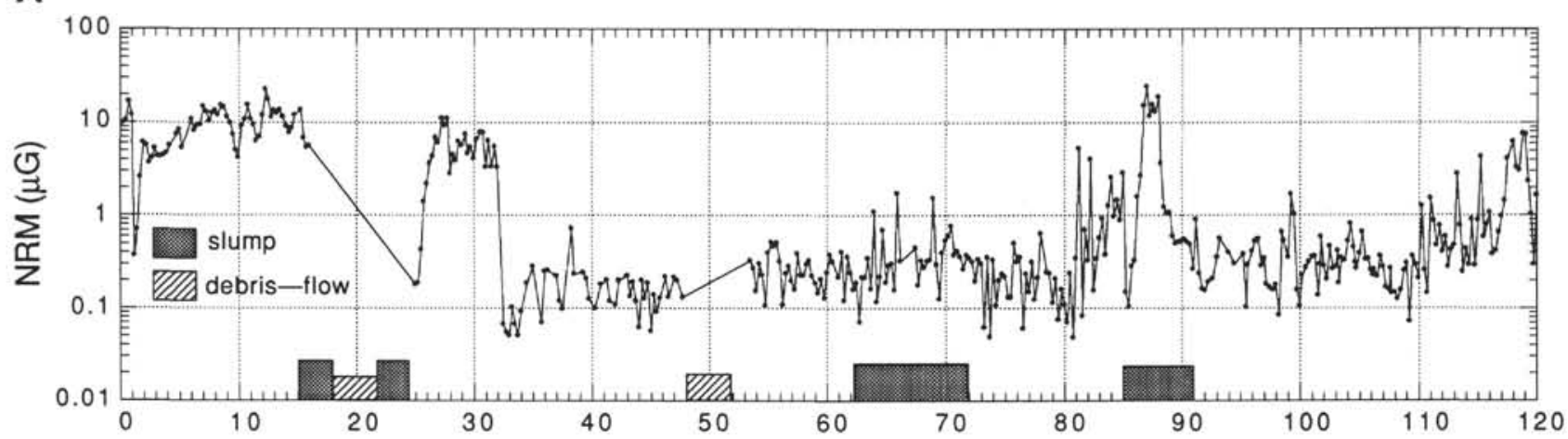

B

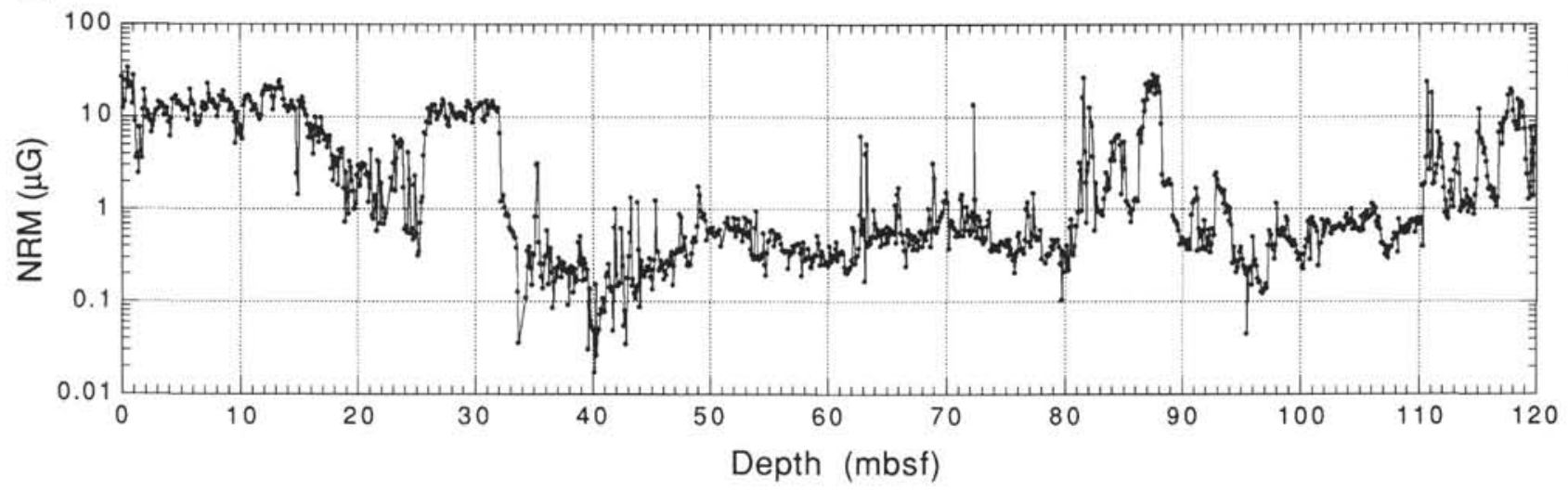

Figure 2. NRM intensity taken aboard the ship. A. Subsamples. B. Whole-core measurements.

Table 1. VRM acquisition data for Hole 823A.

\begin{tabular}{r|r|r|r}
\hline $\begin{array}{r}\text { Depth } \\
(\mathrm{mbsf})\end{array}$ & $\begin{array}{c}\text { NRM } \\
(\mu \mathrm{G})\end{array}$ & \begin{tabular}{c}
\multicolumn{1}{|c}{$\mathrm{K}$} \\
$(\mu \mathrm{G} / \mathrm{Oe})$
\end{tabular} & $\begin{array}{c}\text { VRM/NRM(\%) } \\
(\mathrm{mbsf})\end{array}$ \\
\hline 3.49 & 4.263 & 10.526 & 78 \\
7.01 & 14.799 & 16.392 & 39 \\
9.76 & 5.029 & 11.903 & 51 \\
15.75 & 5.407 & 7.805 & 36 \\
28.25 & 4.538 & 12.886 & 55 \\
38.26 & 0.722 & 5.201 & 42 \\
47.28 & 0.201 & 5.117 & 104 \\
56.78 & 0.284 & 5.541 & 71 \\
66.26 & 0.324 & 4.354 & 74 \\
75.76 & 0.501 & 2.924 & 38 \\
83.51 & 0.377 & 6.444 & 86 \\
87.51 & 15.477 & 35.959 & 50 \\
95.26 & 0.386 & 7.988 & 121 \\
104.27 & 0.816 & 7.203 & 42 \\
113.76 & 0.250 & 3.288 & 159 \\
\hline
\end{tabular}

of peaks at 80 to $90 \mathrm{mbsf}$ and at 110 to $120 \mathrm{mbsf}$. The positions of the zones of major slumps and debris-flow deposits, transcribed from Figure 10 of the initial Site 823 findings (Shipboard Scientific Party, 1991, p. 692), are marked in Figure 2A. The prominent peak at around $88 \mathrm{mbsf}$ lies within a slump deposit.

In the uppermost meter of the sequence, a relatively high remanence (and high ARM and SIRM, see below) suggests the presence of fresh, primary, detrital iron oxides that have been unaffected by progressive sulfate reduction as the sediment aged (Karlin and Levi, 1983). Immediately below this lies a thin zone of low NRM intensity (1.23-1.46 mbsf).

Good agreement is seen between the subsample and the wholecore NRM results. A comparison of the two NRM records shows that the interpolation lines spanning the two missing parts of the subsam- ple record (at 16-25 mbsf and 48-53.5 mbsf) are a reasonable approximation of the actual record. The same holds for the susceptibility, ARM, and SIRM records discussed below. However, these subsamples have NRM values that are typically about $50 \%$ lower than those for the whole-core measurements. The magnitude of the effect is irregular, indicating that it is likely to reflect a change of NRM, possibly a VRM, rather than a calibration problem.

\section{Progressive AF Demagnetization}

Progressive AF demagnetization was completed for 24 pilot specimens distributed throughout the sequence. Demagnetization steps attempted were usually $0,25,50,100,150,200,300,400$, and 500 Oe.

A soft (viscous) component of magnetization is common throughout the sequence and is particularly prominent in the low NRM zones, leading to low MDF values (Table 2). After removal of the soft VRM component (in alternating fields of less than $50 \mathrm{Oe}$ ), the upper $16 \mathrm{~m}$ of the sequence is characterized by a single, stable, normal component of magnetization. The surface sample $(0.23 \mathrm{mbsf})$ has a stable inclination of $-36^{\circ}$, which is closer to the axial dipole value $\left(-31^{\circ}\right)$ than to the present-day inclination $\left(-45^{\circ}\right)$, suggesting that near-surface sediments have not been remagnetized by the present-day field. The one sample (at $28.25 \mathrm{mbsf}$ ) in the high intensity zone in Core $4 \mathrm{H}$ gave a very steep stable component of magnetization, that possibly was caused by a drilling-induced remanence.

Specimens from the "background" zone below $32 \mathrm{mbsf}$, with very low NRM $(<0.5 \mu \mathrm{G})$, produced demagnetization plots that were generally more scattered, often because of the problems of measuring the low magnetizations (in the $10^{-8} \mu \mathrm{G}$ range). Many specimens became too weak to measure after demagnetization much beyond about $300 \mathrm{Oe}$, and sometimes it was not possible to get consistent results beyond $150 \mathrm{Oe}$. The typical behavior is a soft VRM, generally removed in fields of less than a few hundred oersteds, superimposed 
on a single, harder component. Often the demagnetization could not be continued to sufficiently high fields to define the hard component accurately. Less scattered results and higher MDFs (see below) were obtained in the more strongly magnetized specimens.

\section{Median Destructive Field}

Values of MDF (i.e., the demagnetizing field required to halve the initial NRM) have been plotted in Figure 3. Samples from the top 32 $m$ of the sequence have the highest MDF values, usually $>200 \mathrm{Oe}$, and samples from the low magnetization "background" zone beneath have low MDFs, always less than $100 \mathrm{Oe}$, with several values below 50 Oe. The shape of the MDF plot resembles the NRM intensity plot (Fig. 2), indicating a positive correlation between NRM intensity and MDF. This is illustrated more clearly by a plot of NRM vs. MDF (Fig. 4), which shows an approximately linear relationship between MDF and the logarithm of NRM. The low values of MDF result from the large soft magnetic component in the low magnetization zones, where there appears to be no correlation with NRM intensity.

\section{Inclination and Magnetic Polarity}

Above $100 \mathrm{mbsf}$, polarities of the progressively demagnetized specimens are consistently normal, although one sample (at 47.28 mbsf) gave inclinations that oscillated about zero during demagnetization. Based on shipboard biostratigraphic evidence, the B/M boundary was expected to be in the region of 60 to $70 \mathrm{mbsf}$. No evidence of this is found in the paleomagnetic record. However, some evidence for a reversal in specimens between 100.51 and $116.01 \mathrm{mbsf}$ does exist. The specimen at $100.51 \mathrm{mbsf}$ has near-zero inclination (more positive than negative); inclinations at 104.27 and $109.01 \mathrm{mbsf}$ swing to positive values in the final demagnetization step ( 300 and $150 \mathrm{Oe}$ respectively); the specimen at $113.76 \mathrm{mbsf}$ is anomalous, having extremely high coercivity, virtually unaffected by fields up to $400 \mathrm{Oe}$, but shallow, well-scattered, positive inclination; and the specimen at $116.01 \mathrm{mbsf}$ has a well-defined, steeply reversed magnetization. The specimen at the base of the sequence is normally magnetized. These polarity assignments has been summarized in Table 2 .

The remainder of the collection was AF demagnetized at $150 \mathrm{Oe}$. The inclination results, and those of the shipboard measurements (also AF cleaned at $150 \mathrm{Oe}$ ) are shown in Figure 5 . Tram lines on the plot denote axial dipole inclinations $\left( \pm 31^{\circ}\right)$. Directions oscillate about the normal axial dipole value, with intervals of intermediate (low) inclination at 80 to 85,98 to 101,110 to 114 , and below 117 mbsf. There are no intervals of reversed inclination, apart from one single-point spike. The declination record is more difficult to interpret because of the absence of reliable azimuthal orientation data and does not provide further information about reversal boundaries.

It is still not clear to what extent VRM (possibly aided by diagenetic alteration) has obscured the primary remanence. Above $95 \mathrm{mbsf}$, no evidence of a hard primary component can be found. However, the progressive demagnetization data from below 95 mbsf indicate that there is a possibility of gaining further information if more detailed demagnetizations were undertaken, provided measurements could be made in the $10^{-8}$ to $10^{-9} \mathrm{G}$ range. As the record stands it would be unwise to make any magnetostratigraphic interpretation, although some of the intervals of intermediate polarity might possibly be treating as normally overprinted primary reversed intervals.

\section{ROCK MAGNETIC PROPERTIES}

\section{Magnetic Susceptibility}

Measurements of low-field magnetic susceptibility per unit volume were performed on all subsamples. The results (Fig. 6A) are in

Table 2. Data for progressive demagnetization specimens from Hole 823A.

\begin{tabular}{rrrrrl}
\hline $\begin{array}{r}\text { Depth } \\
(\mathrm{mbsf})\end{array}$ & \multicolumn{1}{c}{$\begin{array}{c}\mathrm{NRM} \\
(\mu \mathrm{G})\end{array}$} & $\begin{array}{c}K \\
(\mu \mathrm{G} / \mathrm{Oe})\end{array}$ & $\begin{array}{c}Q \\
(\mathrm{Oe})\end{array}$ & $\begin{array}{r}\text { MDF } \\
(\mathrm{Oe})\end{array}$ & \multicolumn{1}{c}{ Polarity } \\
\hline 0.23 & 9.4682 & 10.229 & 0.926 & 275.0 & $\mathrm{~N}$ \\
3.49 & 3.7001 & 10.526 & 0.352 & 249.6 & $\mathrm{~N}$ \\
7.01 & 14.5110 & 16.392 & 0.885 & 241.9 & $\mathrm{~N}$ \\
9.76 & 5.0366 & 11.903 & 0.423 & 190.7 & $\mathrm{~N}$ \\
15.75 & 5.4162 & 7.805 & 0.694 & 323.8 & $\mathrm{~N}$ \\
28.25 & 4.4480 & 12.886 & 0.345 & 236.7 & $\mathrm{~N}$ \\
38.26 & 0.6496 & 5.201 & 0.125 & 73.0 & $\mathrm{~N}(?)$ \\
47.28 & 0.1342 & 5.117 & 0.026 & 57.7 & $1 \sim 0$ \\
56.78 & 0.2841 & 5.541 & 0.051 & 43.0 & $\mathrm{~N}$ \\
61.76 & 0.3580 & 3.796 & 0.094 & 26.3 & $\mathrm{~N}$ \\
66.26 & 0.2274 & 4.354 & 0.052 & 73.7 & $\mathrm{~N}(?)$ \\
71.01 & 0.4170 & 5.928 & 0.070 & 85.2 & $\mathrm{~N}$ \\
75.76 & 0.3976 & 2.924 & 0.136 & 36.6 & $\mathrm{~N}(?)$ \\
80.51 & 0.2380 & 5.928 & 0.040 & 86.2 & $\mathrm{~N}(?)$ \\
83.51 & 0.3871 & 6.444 & 0.060 & 64.8 & $\mathrm{~N}$ \\
87.51 & 15.9748 & 35.959 & 0.444 & 254.5 & $\mathrm{~N}$ \\
90.26 & 0.5520 & 8.611 & 0.064 & 91.3 & $\mathrm{~N} ?$ \\
95.26 & 0.4066 & 7.988 & 0.051 & 181.6 & $\mathrm{~N}$ \\
100.51 & 0.2740 & 6.326 & 0.043 & 133.9 & $\mathrm{I} \sim 0$ (positive bias) \\
104.27 & 0.1674 & 7.203 & 0.023 & 87.0 & $\mathrm{R}(?)$ \\
109.01 & 0.3060 & 4.043 & 0.076 & 32.4 & $\mathrm{R}(?)$ \\
113.76 & 0.2760 & 3.288 & 0.084 & 500.0 & $\mathrm{R}(?)$ \\
116.01 & 1.0700 & 3.122 & 0.343 & 90.2 & $\mathrm{R}$ \\
120.01 & 1.7228 & 13.372 & 0.129 & 140.6 & $\mathrm{~N}$ \\
& & & & & \\
\hline & & & & & \\
\hline
\end{tabular}

Notes: $\mathrm{I} \sim 0$ denotes very shallow inclination; (?) denotes uncertain polarity assignment. 


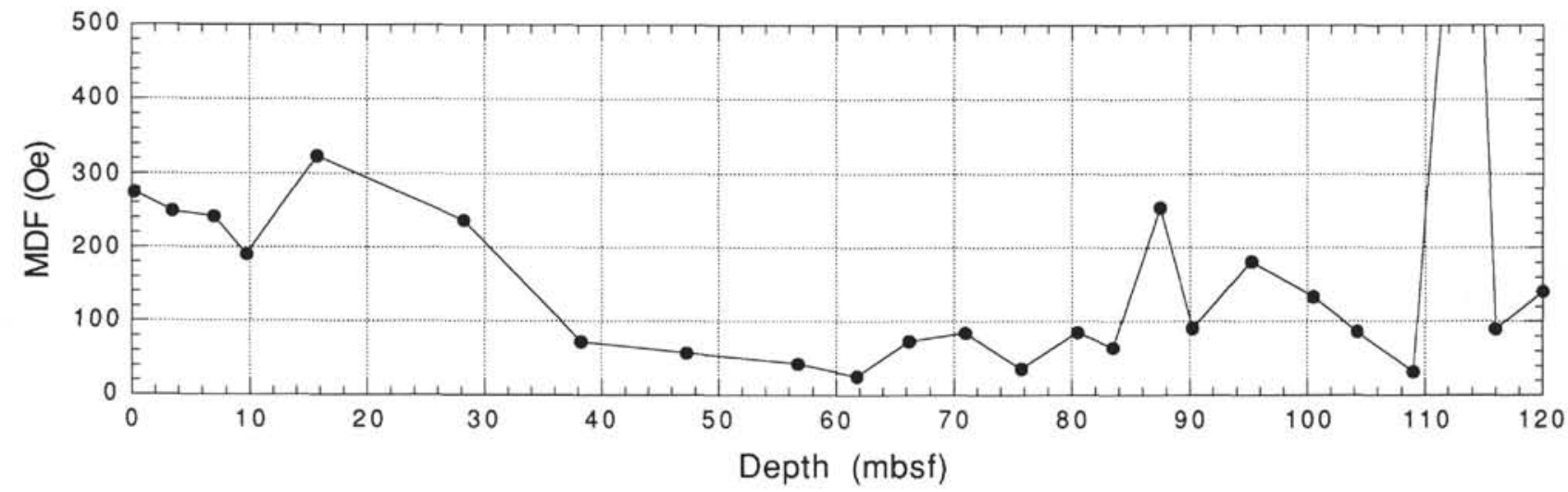

Figure 3. Stratigraphic plot of median destructive field (MDF) for specimens subjected to progressive AF demagnetization. MDF is the demagnetizing peak field required to half the NRM. The specimen at $113.76 \mathrm{mbsf}$ failed to reach the half-intensity level and plots off the scale.

complete agreement with the shipboard whole-core data (Fig. 6B), allowing for the fact that the shipboard measurements were done at low sensitivity (hence, the jumpy nature of the shipboard record). Moderate susceptibilities occur in the upper $32 \mathrm{~m}$ of the sequence (typically about $10 \mu \mathrm{G} / \mathrm{Oe}$ ), then decrease to about $3 \mu \mathrm{G} / \mathrm{Oe}$ at about $40 \mathrm{mbsf}$, and, thereafter, tend to increase slightly with depth down to 120 mbsf. Superimposed on this background pattern are several susceptibility peaks, identified as 1 to 9 in Figure $6 \mathrm{~A}$ and listed in Table 3.

\section{$Q$-Ratio}

The modified Koenigsberger ratio $(Q=\mathrm{NRM} / K)$ provides a measure of magnetic stability as well as a useful indicator of changes in magnetic properties. The $Q$-ratio record is shown in Figure 7. Values in the upper, more strongly magnetic part of the sequence, down to $32 \mathrm{mbsf}$, are relatively high (typically in the range of 0.3 to $1.0 \mathrm{Oe}$ ), which is consistent with the good magnetic stability in this part of the record. Below $32 \mathrm{mbsf}, Q$-ratios are low, typically less than $0.1 \mathrm{Oe}$, with higher values in susceptibility Peak $7(\sim 0.5 \mathrm{Oe})$ and values oscillating about 0.2 Oe in the vicinity of Peaks 8 and 9 . These isolated high $Q$ spikes have been caused by abnormally low susceptibilities and are of no great significance. The $Q$-ratio record, taken as an indicator of magnetic stability (hardness), is consistent with the MDF data (Fig. 3), except at 95.26 and $113.76 \mathrm{mbsf}$, where low $Q$ values coincide with high MDFs. The very low values of $Q$ in the "background" zone are consistent with the magnetic stability and a preponderance of VRM.

\section{$\mathrm{CaCO}_{3}$ Variations}

The shipboard record of total $\mathrm{CaCO}_{3}$ variations is illustrated in Figure 8. Although the carbonate record lacks detail, there appears to be only a weak inverse correlation with susceptibility (Fig. 6), indicating that carbonate dilution is only a minor factor in controlling the observed variations in susceptibility. Susceptibility Peaks 3, 7, and 9 each coincide with carbonate lows, but Peak 5 does not, and the carbonate lows at 54 and about 95 mbsf do not correspond to any obvious features in the susceptibility record. The change in magnetic properties at $32 \mathrm{mbsf}$ does not show up in the carbonate record, and, conversely, the boundary between Subunits IA and IB at $85.4 \mathrm{mbsf}$, although recognizable in the carbonate record, is not seen in the susceptibility record.

\section{ARM and SIRM}

Measurements of anhysteretic remanent magnetization (ARM), imparted in a DC field of $0.4 \mathrm{Oe}$ and an AC exciting field of $1000 \mathrm{Oe}$,

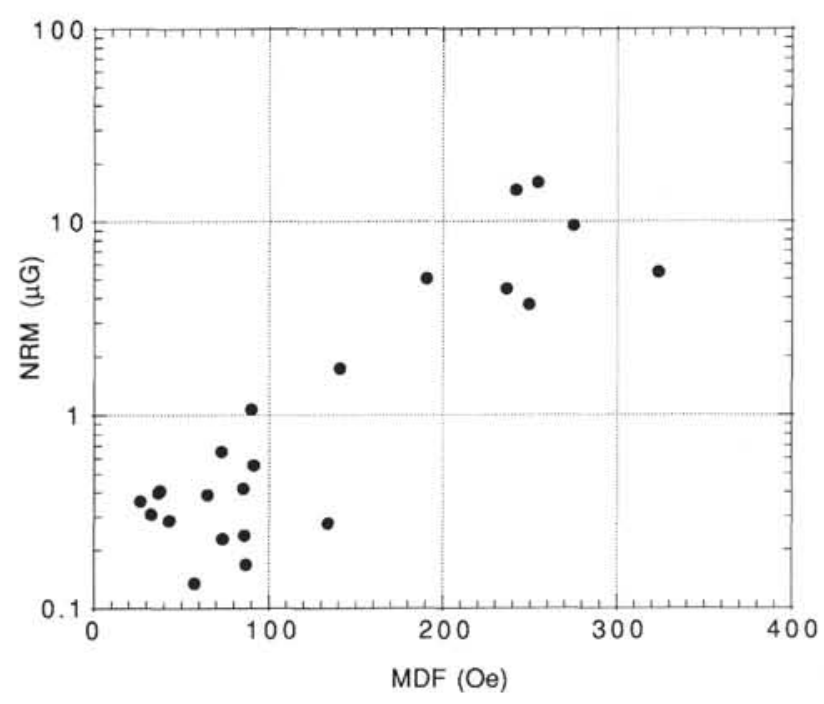

Figure 4. Plot of NRM intensity vs. MDF. The plot shows a positive correlation for higher NRM and MDF values. Note that the NRM scale is logarithmic.

were performed on alternate specimens throughout the sequence. The resulting record (Fig. 9) is similar in shape to the NRM intensity record, which has also been reproduced in Figure 9. Susceptibility Peaks 5, 6, 7, and 8 are all clearly represented in the ARM record (6 and 8 now being more prominent). Peak 4 has been displaced slightly, and susceptibility Peaks 1,2 and 3 do not stand out in the ARM record.

Subsequently, the same set of specimens was given a near-saturation IRM (in a DC field of 5000 Oe) referred to herein as a "SIRM" for convenience. The record obtained (Fig. 9) is similar in shape to the ARM record, except that the SIRM is typically 40 times greater than the ARM in the upper $32 \mathrm{~m}$ of the sequence and about 25 times greater below this level. Furthermore, Peaks 2, 3, and 4 are clearly defined in the SIRM record.

The contrasts between the magnetic properties of the strong and weak "background" zones and these peaks are well illustrated on an ARM-susceptibility diagram (Fig. 10). In such a diagram, high $\mathrm{ARM} / K$ ratios are indicative of a stable remanence (commonly carried by single-domain magnetite in lacustrine and many marine environments), whereas low ratios are characteristic of multidomain or superparamagnetic assemblages (Banerjee et al., 1981; King et al., 1982). Groups of points clustering about straight lines through the origin have a common magnetic composition/grain-size distribution with varying concentration of magnetic material (Thompson and 
A

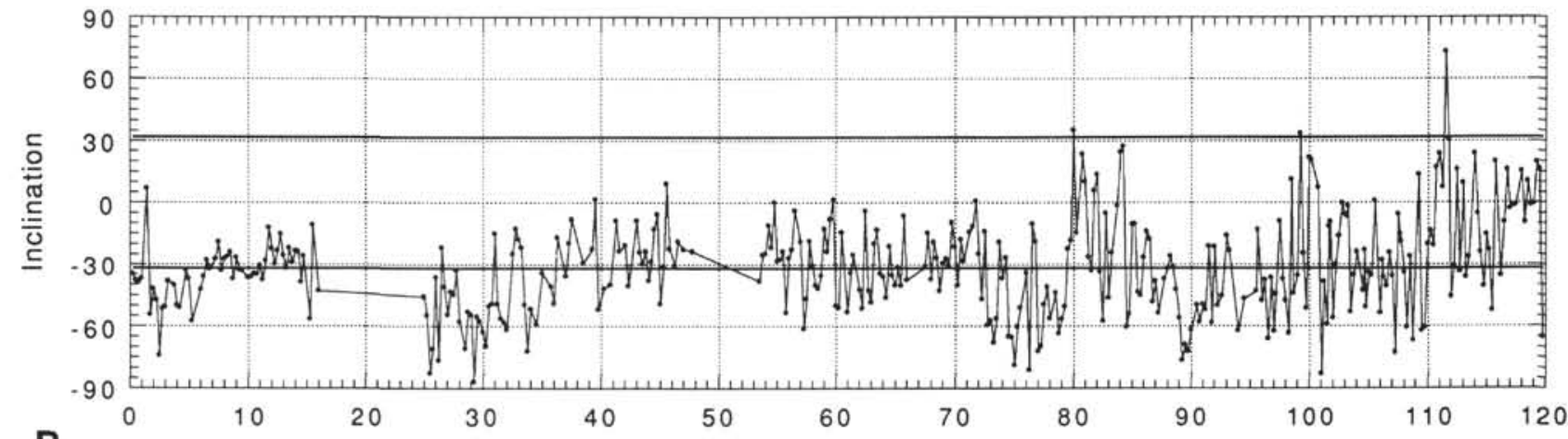

B

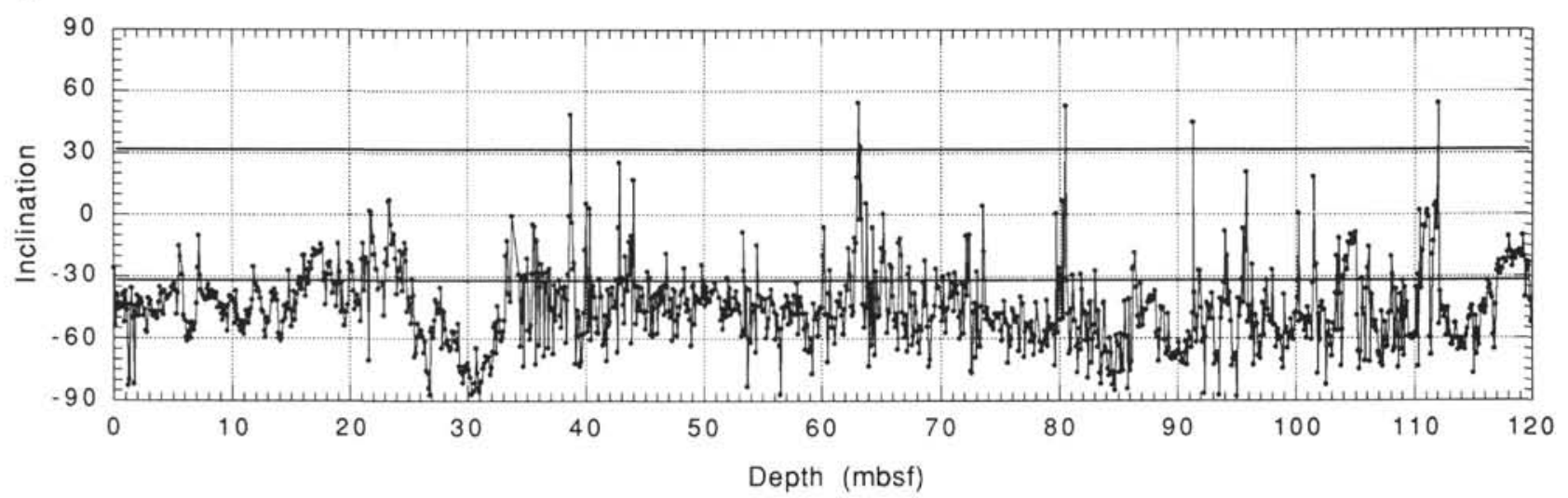

Figure 5. Magnetic inclination after AF magnetic cleaning at $150 \mathrm{Oe}$ for (A) subsample and (B) whole-core measurements. The tram lines are the geocentric axial dipole directions for reversed and normal fields $\left( \pm 31^{\circ}\right.$ respectively).

Table 3. Positions of the main susceptibility peaks.

\begin{tabular}{ccc}
\hline $\begin{array}{c}\text { Peak } \\
\text { number }\end{array}$ & $\begin{array}{c}\text { Depth range } \\
(\mathrm{mbsf})\end{array}$ & $\begin{array}{c}\text { Max. susceptibility } \\
(\mu \mathrm{G} / \mathrm{Oe})\end{array}$ \\
\hline 1 & $0.23-0.98$ & 30.6 \\
2 & $6.76-9.00$ & 25.1 \\
3 & $13.24-14.01$ & 29.2 \\
4 & $26.75-27.51$ & 18.0 \\
5 & $30.51-31.01$ & 12.6 \\
6 & $84.01-84.01$ & 14.6 \\
7 & $86.76-88.26$ & 39.2 \\
8 & $113.26-113.26$ & 16.8 \\
9 & $117.51-119.01$ & 35.5 \\
\hline
\end{tabular}

Oldfield, 1986). The distribution of points in Figure 10 has been divided into Group A (ARM $/ K \sim 0.7 \mathrm{Oe})$, Group B (ARM/ $K$ between 5 and $12 \mathrm{Oe})$, and Group $\mathrm{C}(\mathrm{ARM} / K>12 \mathrm{Oe})$. The demarkation of characteristic $\mathrm{ARM} / K$ ratios shows up clearly when these $\mathrm{ARM} / K$ ratios are plotted as a function of depth (Fig. 11). Figures 10 and 11 reveal several interesting features:

1. The low magnetization background sediments below $32 \mathrm{mbsf}$ give points tightly clustered about a line of low gradient ( $\sim 0.7 \mathrm{Oe})$, comprising Group A.

2 . The intervals between the susceptibility peaks above $32 \mathrm{mbsf}$ have the highest $\mathrm{ARM} / K$ ratios $(>=15 \mathrm{Oe})$ and fall into Group $\mathrm{B}$.

3. Points from the set of weaker susceptibility peaks $(5,6$, and 8$)$ have high $\mathrm{ARM} / K$ ratios ( $>12$ Oe) and also fall into Group B; susceptibility Peak 5 stands out as being anomalous with very high $\mathrm{ARM} / K$ ratios.
4. Points from the set of stronger susceptibility peaks $(2,3,4,7$, and 9) are loosely grouped with intermediate $\mathrm{ARM} / K$ ratios ( 6 to $12 \mathrm{Oe}$ ) and comprise Group C. Below $32 \mathrm{mbsf}$ in Figure 11, they appear as maxima because of the low background values of $\mathrm{ARM} / K$, whereas above 32 mbsf, they appear as minima because of high background values.

Susceptibility values for Peaks 5, 6, and 8 are similar to those for the intervals between peaks in the upper part of the sequence (above $32 \mathrm{mbsf}$ ); thus, it is not too surprising that these fall into the same group in the ARM vs. $K$ diagram. There are insufficient measurements to resolve the status of Peak 1.

Above $32 \mathrm{mbsf}$, the susceptibility and $\mathrm{ARM} / K$ records are inversely correlated, whereas below $32 \mathrm{mbsf}$, there appears to be a switch to positive correlation (the main peaks in the two records match). However, the latter effect might simply be a consequence of low background ratios, making intermediate $\mathrm{ARM} / K$ ratios stand out as peaks.

\section{Other Tests}

Measurements of IRM as a function of applied field (up to 5000 Oe) were performed on seven specimens from the background zone. The level of saturation attained varied from complete saturation in 2000 Oe at 90.26 mbsf to well below saturation in 5000 Oe at 116.01 mbsf (where the gradient of the normalized IRM curve was $36 \times 10^{-6}$ $\left.\mathrm{Oe}^{-1}\right)$. Thus, there appears to be a highly variable contribution from high-coercivity grains (hematite-type). No pattern was obvious in the results obtained, nor was there correlation with any of the other parameters measured.

Lowrie-Fuller tests (Lowrie and Fuller, 1971; Dunlop, 1983) were performed on the same set of specimens. All gave similar results, with 


\section{A}
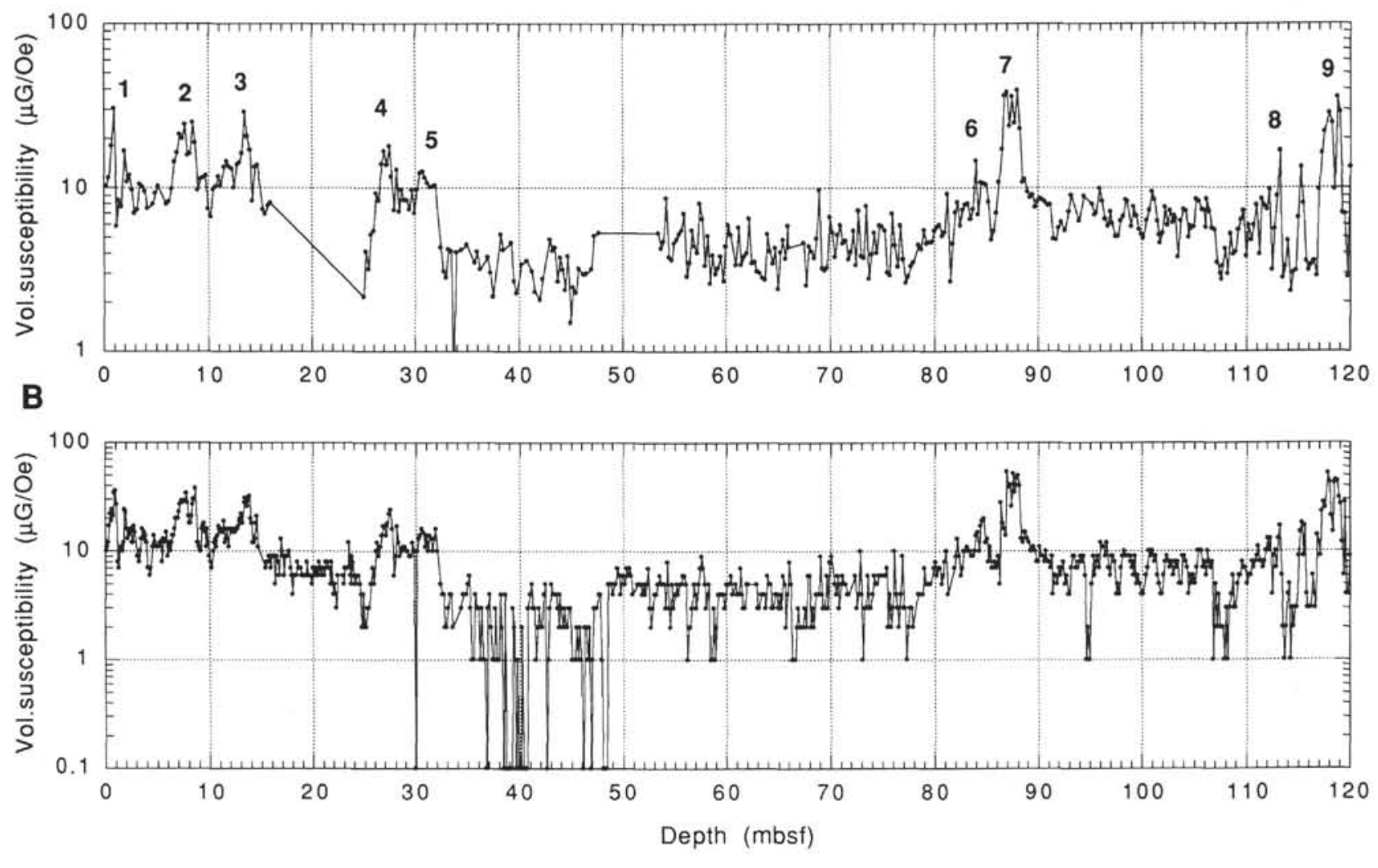

Figure 6. A. Volume susceptibility record for Hole 823A. Susceptibility peaks that are discussed in the text have been labeled 1 though 9. B. Corresponding shipboard whole-core record, that provides information for the gaps in the subsample record. The jumpy nature of the record results from the coarse resolution of the shipboard measurements.

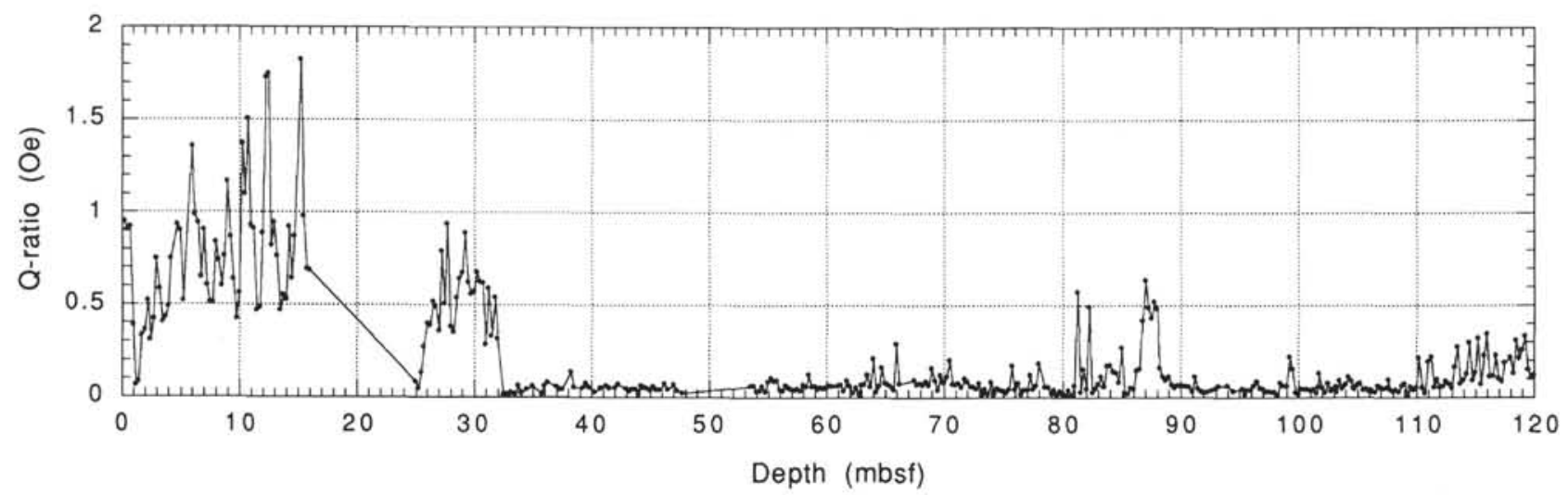

Figure 7. $Q$-ratio $(=\mathrm{NRM} / K)$ record for Hole $823 \mathrm{~A}$.

ARM being harder than SIRM (in 5000 Oe) initially and with a cross-over to SIRM harder than ARM after 300 to 400 Oe. One specimen, at $80.51 \mathrm{mbsf}$, had this cross-over at about $250 \mathrm{Oe}$.

The results of the IRM acquisition and Lowrie-Fuller tests indicate that a simple multidomain explanation for the poor magnetic stability and large VRM in the weak background zone is an over-simplification.

\section{DISCUSSION AND CONCLUSIONS}

The natural remanence of sediments from Hole $823 \mathrm{~A}$ is dominated by a VRM acquired during the Brunhes Chron that obscures any primary reversal stratigraphy. Assignment of polarities lower in the sequence (as summarized in Table 1) is problematic in view of this VRM. It is also possible that the hard components of magnetization that have been isolated from the soft viscous overprinting during progressive demagnetization are still of viscous origin, although an overprint component of authigenic or diagenetic origin is probably present. AF cleaning was not effective in isolating a primary magnetization, but could not be taken to peak fields much in excess of 300 to 400 Oe because of the very weak magnetizations in much of the sequence. Samples from the "background" zone of weakly magnetized sediments gave negative Lowrie-Fuller test results, suggesting 


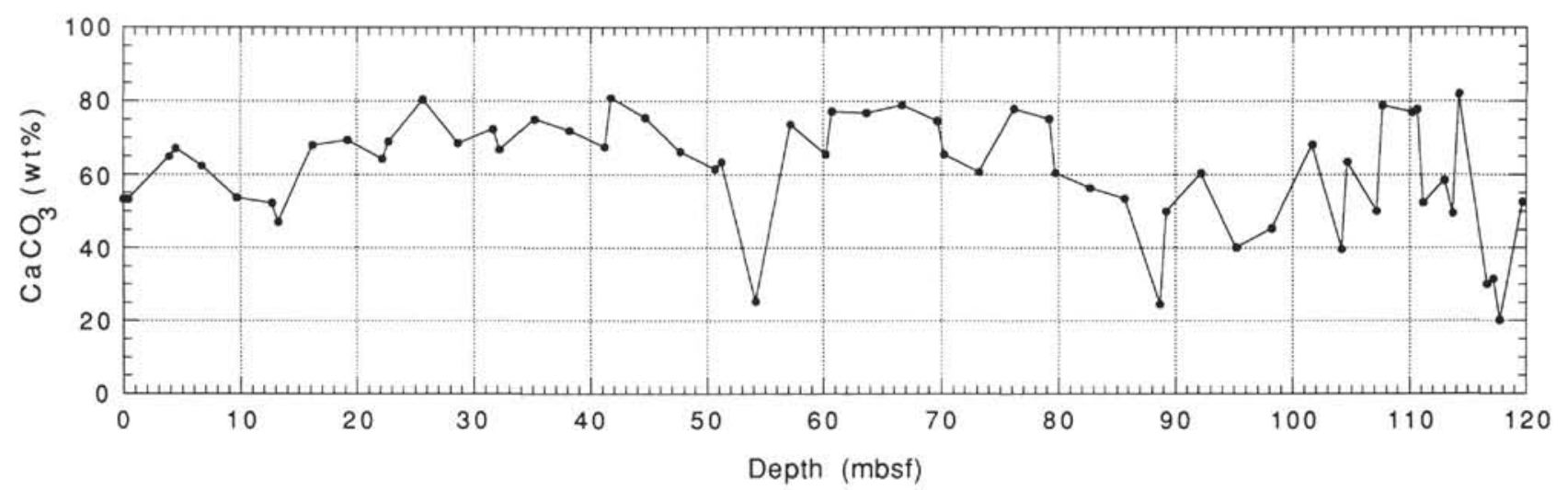

Figure 8. Downcore variation of total $\mathrm{CaCO}_{3}$, expressed as weight percent. Data taken from Table 3 of the Initial Reports volume for Site 823 (Shipboard Scientific Party, 1991, p. 720).

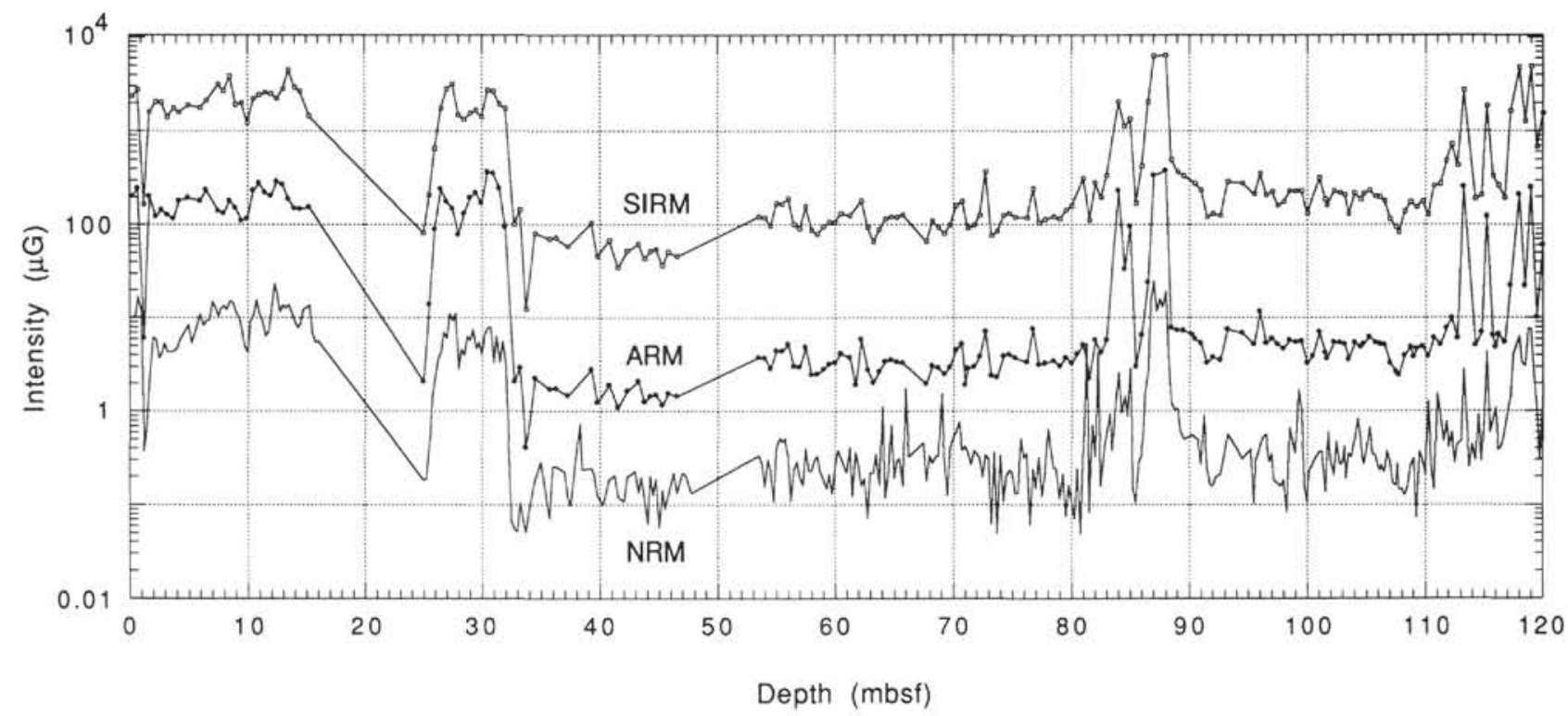

Figure 9. ARM and SIRM records for Hole 823A. ARM is imparted in a DC field of 0.4 Oe with an AC exciting field of 1000 Oe. The SIRM is imparted in a DC field of $5000 \mathrm{Oe}$, which produces near-saturation, but not complete saturation. The NRM record is reproduced for comparison.

that the VRM overprint does not have a simple multidomain magnetite origin. Furthermore, a variable high coercivity (hematite-type) fraction is present in this zone.

No evidence was found in the magnetic record for a distinction between Subunits IA and IB. The principal magnetic boundary in the sequence occurs at $32 \mathrm{mbsf}$, below which the "background" magnetization is very weak and has a distinctive, very low ARM $K$ ratio. This magnetic boundary appears to coincide more-or-less with the division between the sulfate-reduction zone in the upper part of the sequence and the sulfate-free zone beneath. It is well-established that sulfate reduction processes gradually remove the primary detrital iron-oxide signal in marine sediments, causing a steady decline of remanence with depth (Karlin and Levi, 1983). The depth over which the effect is seen often ranges from several meters to several tens-of-meters below seafloor. A sharp decrease in remanence, such as one sees in Hole $823 \mathrm{~A}$ at $32 \mathrm{mbsf}$, is most unusual in this context, and is indicative of a hiatus at $32 \mathrm{mbsf}$. Examination of the whole-core NRM record (Fig. 2B) suggests that a steady sulfate-reduction-induced decrease of remanence with depth is present in the slump and debris-flow deposits between 16 and 25 mbsf (and possibly continuing from 32 to $40 \mathrm{mbsf}$, which is the lower boundary of the sulfate-reduction zone). This gravity-flow interval intrudes into a zone of stable, strongly magnetized sediments ( 10 to $20 \mu \mathrm{G}$ ) that may be resistant to sulfate-reduction effects.

Thus, the boundary at $32 \mathrm{mbsf}$ must have major significance apart from its relationship with the sulfate reduction/sulfate-free boundary. This boundary may well be linked to the nature of turbidite deposition: above $32 \mathrm{mbsf}$, the turbidite layers are thin (mostly $<6 \mathrm{~cm}$ thick), whereas below 32 mbsf they vary greatly in thickness with many exceeding $20 \mathrm{~cm}$. This turbidite transition shows up clearly in Figure 10 of the Site 823 report (Shipboard Scientific Party, 1991, p. 692). The reason for this, and the relationship with the relatively high, stable remanence of the sediments above $32 \mathrm{mbsf}$, has yet to be identified.

Note that the boundary at $32 \mathrm{mbsf}$ occurs in the vicinity of the boundary between nannofossil Subzone CN14a and Zone CN15, as reported by the Shipboard Scientific Party (1991). Subzone CN14b was not identified and was suspected of being lost in a hiatus in Core $4 \mathrm{H}$. The abrupt nature of this magnetic boundary suggests that this hiatus occurs at $32 \mathrm{mbsf}$.

The magnetic properties of the sediments fall into three main groups having characteristic ranges of $\mathrm{ARM} / K$ ratios: Group $\mathrm{A}$, with very low ratios (near $0.7 \mathrm{Oe}$ ); Group $\mathrm{B}$, with high ratios (>12 Oe), and Group $\mathrm{C}$, with intermediate ratios (between 5 and $12 \mathrm{Oe}$ ). These groupings of $\mathrm{ARM} / K$ ratios were determined largely by the magnitude 


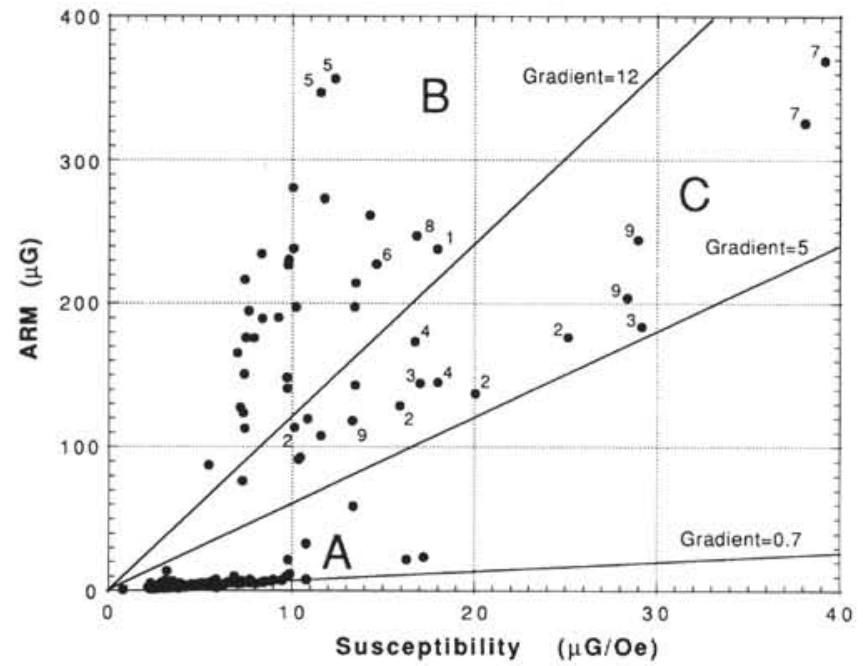

Figure 10. ARM plotted vs. magnetic susceptibility. The data fall essentially into three regions: Group $\mathrm{A}$, with very low $\mathrm{ARM} / K$ ratios (clustered about a line of gradient $0.7 \mathrm{Oe}$ ); Group $\mathrm{C}$, with intermediate $\mathrm{ARM} / K$ ratios (5 to 12 Oe); and Group B, with high ARM $/ K$ ratios ( $>12$ Oe). Group A data come from the low magnetization background zone below $32 \mathrm{mbsf}$; points in Group $\mathrm{C}$ are from the stronger set of susceptibility peaks (2, 3, 4, 7, and 9); and points in Group B are from the intervals between peaks above $32 \mathrm{mbsf}$, together with the weaker pair of peaks ( 6 and 8 ). Peak 5 is anomalous and has very high $\mathrm{ARM} / K$ ratios that plot in Group B. The numeric labels in the figure denote the individual susceptibility peaks.

of the susceptibility: (1) the low susceptibility "background" zone below $32 \mathrm{mbsf}$ has very low ARM/K ratios; (2) intermediate susceptibilities (around $10 \mu \mathrm{G} / \mathrm{Oe}$ ), comprising the intervals between the peaks above 32 mbsf together with the set of weak susceptibility peaks (5, 6, and 8), have the highest $\mathrm{ARM} / K$ ratios; and (3) the peaks in which susceptibility exceeds $20 \mu \mathrm{G} / \mathrm{Oe}$ are characterized by intermediate $\mathrm{ARM} / K$ ratios.

Some correspondence may exist between these groups and the A, $\mathrm{B}$, and C classes (respectively) of magnetic properties identified at Site 820 (Barton et al., this volume). If so, then sediments in Group $\mathrm{B}$ contain stable single-domain magnetite, and the Group C sediments contain a mixed single-domain and super-paramagnetic contribution-the latter have a relatively high susceptibility (e.g., Thompson and Oldfield, 1986) and might contribute to the high susceptibility peaks). However, a predominantly multidomain magnetite origin for the Group A sediments (following from the Site 820 analogy) is not favored for Hole 823A. The Lowrie-Fuller test results and the presence of some high coercivity material in the background Group A sediments points to a more mixed magnetic mineralogy and/or grainsize distribution.

\section{ACKNOWLEDGMENTS}

I thank Steve Adamson for assistance with laboratory work, and John King for helpful comments. This study is published with the permission of the Executive Director, Australian Geological Survey Organisation.

\section{REFERENCES}

Banerjee, S.K., King, J., and Marvin, J., 1981. A rapid method for magnetic granulometry with applications to environmental studies. Geophys. Res. Lett., 8:333-336.

Davies, P.J., McKenzie, J.A., Palmer-Julson, A., et al., 1991. Proc. ODP, Init. Repts., 133: College Station, TX (Ocean Drilling Program).

Dunlop, D.J., 1983. Determination of domain structure in igneous rocks by alternating field and other methods. Earth. Planet. Sci. Lett., 63:353-367.

Karlin, R., and Levi, S., 1983. Diagenesis of magnetic minerals in recent hemipelagic sediments. Nature, 303:327-330.

King, J., Banerjee, S.K., Marvin, J., and Ozdemir, O., 1982. A comparison of different magnetic methods for determining the relative grain size of magnetite in natural materials: some results from lake sediments. Earth Planet. Sci. Lett., 59:404-419.

Lowrie, W., and Fuller, M., 1971. On the alternating field demagnetization characteristics of multidomain thermoremanent magnetization in magnetite. J. Geophys. Res., 76:6339-6349.

Shipboard Scientific Party, 1991. Site 823. In Davies, P.J., McKenzie, J.A., Palmer-Julson, A., et al., Proc. ODP, Init. Repts., 133 (Pt. 1): College Station, TX (Ocean Drilling Program), 679-768.

Thompson, R., and Oldfield, F., 1986. Environmental Magnetism: London (Allen and Unwin).

\footnotetext{
- Abbreviations for names of organizations and publication titles in ODP reference lists follow the style given in Chemical Abstracts Service Source Index (published by
} American Chemical Society).

Date of initial receipt: 30 June 1992

Date of acceptance: 5 January 1993

Ms 133SR-262

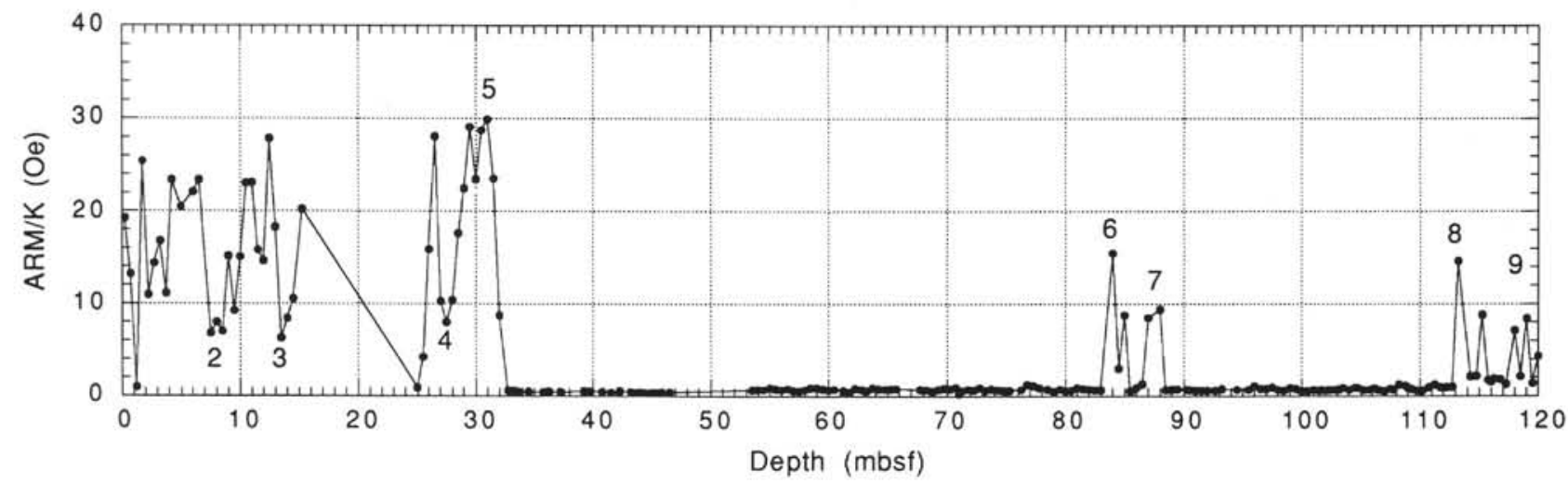

Figure 11. Plot of the ratio of ARM/K as a function of sub-bottom depth in Hole 823A. The numbered peaks and troughs correspond to the susceptibility peaks in Figure 6. 